\title{
Development status, problems and policy suggestion of 5G
}

\author{
YE Xiumin \\ Center for Informatization Study of Chinese Academy of Social Sciences, Beijing, China \\ xmye@cass.org.cn
}

Keywords: 5G; Mobile communications; Internet of things

\begin{abstract}
G has the advantages of high reliability, low ductility, high speed , etc. 5G not only can greatly enhance the experience of internet users, but also detonate the transformation and development of traditional industries such as industrial internet, artificial intelligence, mobile medical and other fields. 5G has become the main battlefield of a new round information technology competition in the world. Countries have deployed 5G development strategy, and actively promoted R \& D and commercial. They are all trying to gain global leadership in the future.
\end{abstract}

\section{Introduction}

With the users' increasing demand for network performance and the continuous innovation of mobile communication technology, the fifth generation mobile communication technology (also known as the fifth generation mobile phone communication standard, referred to as: $5 \mathrm{G}$ ) comes into being. Compared with 4G, 5G will bring faster transmission rate, higher traffic density, lower transmission delay, more reliable network connection and more flexible system layout [1]. In the Internet age, people and people, people and intelligent terminals link each other; while in the 5G era, people and things, things and things, things and clouds will also link up, and truly realize all things interconnected, everything knowable, everything controllable.

\section{Development status of 5G}

Because 5G closely connects people and people, people and things, things and things, so there will be huge market space in the future. At present, governments and enterprises from all sectors of the industry chain are laying out 5G. They are accelerating the development, testing, business, cooperation and other key areas of work [2].

Deploy 5G development strategy, promote $R \& D$ and commercial use. The major developed countries in the world regard $5 \mathrm{G}$ as an important field of development. They lay out early to get the advantage in the development and commercial aspects, which will lead to the country's economic development and the global implementation in the future. 5G has become the world's main battlefield in the new round of information technology competition. According to these countries' development strategy, 5G will be started commercial applications in 2020.

5G international standards will be introduced. The trend of reunification is obvious. The formulation of technical standards has been the focus of the game between countries, operators and equipment manufacturers. In 3G eras, China Mobile's TD-SCDMA standard broke foreign monopoly, prompting HUAWEI, ZTE and a number of domestic manufacturers rise. In 4G era, China's three major operators insisted different standards. In $5 \mathrm{G}$ era, international standards tend to be unified. The American major operators collectively support Qualcomm program. China's three operators support HUAWEI program.

"Quasi 5G" began to seize the market, accessed to the first mover advantage. 5G technology standards have not yet been introduced, but competition in the 5G market has begun. Many operators began to force ahead of the "quasi 5G" market. "Quasi 5G" is not a true 5G, but an upgrade to existing 4G devices. China's ZTE said that it has deployed more than 40 "quasi 5G" networks in 30 countries worldwide, with the average capacity of single base stations raised by 6.7 
times. Japanese operators Softbank Corp also announced in September 2016 the official commercial " quasi 5G", the original 5GB /5000 Yen on January flow package upgrade to 20GB /6000 Yen on January flow package. Its economic and social benefits reflected immediately.

SDN/NFV promotes communication network, operators will benefit from. SDN/NFV (software defined network / network function virtualization) are two technologies which can promote communication network optimization, shorten the operational service on-line cycle, reduce the operators deployed 5G time and cost[3]. According to HIS technology research, revenues from the global SDN/NFV operator were \$289 million U.S. Dollars in 2015 , which will increase to 8 billion 700 million U.S. Dollars by 2020 with an average annual growth rate of $98 \%$. Some the top operators have realized the commercialization of SDN/NFV. For example, AT\&T has launched the business in 2015, which has provided solutions for more than 1200 enterprises. Its goal is that the $75 \%$ network function can be virtualized to 2020 .

Operators force group business, focusing on the basic service of the Internet things. 5G technologies introduces a new generation of network architecture design concepts that allow businesses to customize and lease network segments of carriers and provide professional maintenance and management by operators. This kind of operation is very suitable for developing group business. In the fast developing North America area, the group business model has entered the stage of practical application, and both Verizon and AT\&T have launched the national commercial network.

Internet companies are stepping into the 5G Market. The continuous innovation of information and communication technology has lowered the access threshold for the communication equipment industry, and a batch of internet companies are stepping into the field of communications. The competitiveness of Internet companies is not to be overlooked. They have the advantages of funds and users, as well as strong innovation ability. The entry of Internet companies is bound to increase the intensity of competition in the global 5G market. Google started "Project Fi" to built global coverage of carrier services. It plans to construct global communications network with hot air balloon, satellite, fiber broadband etc. Its communication services especially want to cover the remote areas.

Equipment manufacturers dedicate to the application of Internet of things research. With the continuous improvement and evolution of 5G technologies, NOKIA, Ericsson, ZTE, HUAWEI, these four equipment manufacturers have introduced their own existing technology matching 5G technology solutions. NOKIA layout in telemedicine, virtual reality and artificial intelligence; Ericsson layout in the remote control driving, intelligent parking, water network and environmental monitoring; ZTE layout in car networking, Industrial networking, intelligent Home Furnishing.

Chip companies takes "5G full set of solutions" as a transformation direction. With the background of industry chain integration in $5 \mathrm{G}$ era, the direction transformation of chip manufacturers is to provide a full range of $5 \mathrm{G}$ solutions from the end to the cloud. In the case of Intel, which announced in 2016 after the transition, 5G will be regarded as a key technology to access the cloud and "always connected the world ". It has laid out 5G through the whole industry chain, from the cloud to the core network, access network, to air interface (Wireless Technology), to the intelligent equipment. Overall, Intel will form an end-to-end $5 \mathrm{G}$ solution in the area of terminal connections, wireless technology, core networks and clouds.

\section{Problems existing in the development of 5G in China}

Chinese government set up an IMT-2020 group for 5G mobile communications research and development, and began to carry out 5G researches in 2013. At present, China's 5G wireless technology and network architecture are in the leading position in the world, and some achievements have been adopted by the International Telecommunication Union. However, China's $5 \mathrm{G}$ development is facing three major challenges.

Technical challenges. Although China has made some achievements in the field of technology development, such as the Polar code pushed by HUAWEI as the short code encoding scheme, the SBA framework pushed by China as the $5 \mathrm{G}$ core framework infrastructure, but the standard has not 
yet been completely frozen[5]. That means Chinese advantage established in the global 5G standard is not obvious. In addition, due to the lack of domestic patent sharing mechanism, the domestic communications enterprises closed their own research and development. So they cannot form a technical force. Therefore, they are at a disadvantage in the international competition, especially in the Sino US communications enterprises. Finally, because some countries are worried about security issues, it may hinder our excellent telecommunications equipment products to enter a broader international market.

Business challenges. The regional demand is different and unbalanced. Each operator's positioning and the application scenarios of $5 \mathrm{G}$ are also different. For example, China's western regions is expected to solve the last mile broadband access problem with 5G; medium city hope solve the problem of mobile Internet experience; while in the first-tier cities, the population density is high and a large number of people often gathered in the holiday consumption area, where the existing spectrum resources are difficult to support. How to deal with this imbalance is a challenge.

Technology R \& D lags behind market demand. In the early days of 5G researches, the demand for mobile communications and the judgment of application scenarios are not completely clear, so there are some obstacles in the process of research and development and integration with practice. For example, unmanned and AR/VR applications are in rapid growth, but the 5G research hasn't put these fast growing demand as an important application scenarios before.

Some traditional industries are not actively involved in 5G applications. In the 5G industry chain, different roles are actively supporting the development of the Internet of things. However some of the industry's participation is not enough, such as traditional electricity, industrial equipment, environmental monitoring etc.

Policy challenges. Cross industry regulatory policies are lacking. The development of 5G requires not only the support of the government's policies and regulations, but also the comprehensive coordination of cross-department regulatory policies. Moreover, the regulatory policies in each field are different. If the policy is fragmented, it will face major challenges to integrate $5 \mathrm{G}$ and Industry development deeply.

The operator's license has not been released in time. TD-SCDMA, WCDMA and CDMA2000 in the $3 \mathrm{G}$ era, and TD-LTE, TD-LTE, FDD-LTE in the 4G era, have encountered resistance in licensing. There are two problems with the delayed issuance of licenses, one is not conducive to operators' early planning and to seize the international market opportunities, the other is to raise the cost of network operators.

\section{Countermeasures and suggestions for the development of $5 \mathrm{G}$ in China}

The development of $5 \mathrm{G}$ is not only an important task for the future development of information technology and industry in China, but also the key to enhance the comprehensive strength and international leading edge of China's information industry. Therefore, the relevant departments should attach great importance to the development of 5G.Countermeasures and suggestions are given below.

Policy promote to seize the initiative. First, the relevant departments should track 5G global progress and focus on disruptive technology research and development, application process. Then, China's applicability in related areas, application time cycle should be assessed. At last, a series of targeted 5G support and guidance policies should be introduced as soon as possible in order to accelerate the development and commercialization. Meanwhile, the relevant departments should release $5 \mathrm{G}$ high quality spectrum resources in time. They also should launch a special support fund which is helpful to breakthroughs in core technologies.

Standard drive and early plan. Both enterprises and institutions should strengthen international exchanges and cooperation. First of all, we should actively promote the candidate program including China's main push technology to become the ITU standard, and obtain the 5G international standard to formulate the discourse power. Secondly, we should pay close attention to the formulation of global or regional industry standards and plan against the regionalization standards that exclude Chinese enterprises. Finally, we should take overall consideration into 
account, grasp the favorable opportunity accurately, accelerate the pace of issuing 5G licenses, encourage healthy and orderly competition among enterprises, and improve the quality of service.

Opening up cooperation and building ecology. The competition of 5G will be not only the competition of a certain technology or standard, but the competition of the whole $5 \mathrm{G}$ industry chain and ecological construction. China should set up a cross - border 5G work coordination team to encourage domestic software and hardware vendors, operators and other equipment providers to cooperate and establish a benign industrial chain. On this basis, open to the traditional partners in the field of application, integration of resources, and manufacturing, business and service industry integration and development, and build a healthy industrial ecology. We should encourage regional actors to establish regional strategic alliances and join hands in international competition.

Run in phases and focus on layout. The commercial 5G should adopt a gradual strategy in the region. The most urgent needs of first-tier cities populated commercial district and transportation hub and remote rural areas should give priority to development, and then popularize gradually to other areas. In the industry choice, industrial Internet, smart home, intelligent driving, telemedicine, virtual reality should focus on layout, and then promote the use of other areas.

\section{References}

[1] China information and Communication Research Institute, 《5G white paper on economic and social impact》, June 2017

[2] Qualcomm Corp, 《5G Economics: how 5G technology will affect the global economy》, March 2017

[3] CHEN Shanzhi, 《Analysis and suggestion of future 5G directions》, 《Telecommunication Science 》, July 2016

[4] ZHOU Yuzhe, 《5G Global Promotion Status Overview and Enlightenment》, 《mobile communication》, 2016. 19.

[5] LI Hui , 《Analysis and Prospect on 5G Network Security》, 《R adio Communications Technology $\rangle$, 2015.(41).4 